\title{
Qual o efeito da violência contra a mulher brasileira na autopercepção da saúde?
}

\author{
What is the effect of violence against Brazilian women on their \\ self-perception of health?
}

Mércia Santos Cruz (https://orcid.org/0000-0002-5823-725X) ${ }^{1}$

Guilherme Irffi (https://orcid.org/0000-0002-3558-7628) ${ }^{2}$

\footnotetext{
${ }^{1}$ Faculdade de Economia, Universidade Federal da Paraíba. Cidade Universitária, Castelo Branco. 58059-900 João Pessoa PB Brasil. mercia_sc@hotmail.com ${ }^{2}$ Departamento de Economia Aplicada e do Programa de Pós-Graduação em Economia, Faculdade de Economia Administração, Atuária, Contabilidade e Secretariado e Executivo, Universidade Federal do Ceará. Fortaleza CE Brasil.
}

\begin{abstract}
This article analyzes the effect of violence against women on their self-perception of health, based on the population of Brazilian women aged between 20 and 49 years of age, using data from the 2013 National Health Survey. The results indicate that more than $80 \%$ of women who suffered violence caused by an individual in the last 12 months prior to the survey, reported the most severe being psychological and/ or physical aggression. The worst health reports were higher among women who reported violence suffered at the hands of a person known to them, in the case of residents in rural areas. With respect to residents of urban locations, there were reports of violence perpetrated by an unknown aggressor. Based on these results, it can be inferred that women who are victims of violence have a worse self-perception of health vis-à-vis those who were not victims of violence.
\end{abstract}

Key words Violence, Self-perception, Health, Women
Resumo $O$ artigo analisa o efeito da violência contra a mulher na autopercepção da saúde, a partir de uma população de mulheres brasileiras com idades entre 20 e 49 anos, considerando as informações da Pesquisa Nacional de Saúde de 2013. Os resultados indicam que mais de $80 \%$ das mulheres que sofreram violência por indivíduo nos últimos doze meses anteriores a pesquisa, relataram como mais grave a agressão psicológica elou física. O pior reporte de saúde foi maior entre mulheres que relataram violência sofrida por pessoa conhecida, em caso de residentes em áreas rurais; já dentre as residentes de localidades urbanas, houve relatos de violência perpetrada por agressor desconhecido. Em função desses resultados, pode-se inferir que as mulheres vitimas de violência possuem pior percepção de saúde vis-àvis as que não foram vítimas de violência.

Palavras-chave Violência, Autopercepção, Saúde, Mulher 


\section{Introdução}

As várias formas de violência às quais as mulheres estão susceptíveis podem acarretar uma miríade de consequências para a integridade física e mental das mesmas, e consequentemente pode elevar à necessidade de atendimento médico. Essas intercorrências podem trazer implicações à qualidade de vida da mulher, além de externalidades para a sociedade como um todo. Assim, postulase que além da demanda por acolhimento clínico provocado pelos atos de violência, é possível que mulheres vítimas de violência tenham pior percepção do seu estado de saúde, comparativamente às consortes não agredidas.

Como a saúde de uma pessoa depende de sua condição física, social e mental, é provável que o bem-estar de mulheres que sofreram violências seja inferior ao das mulheres não acometidas pelo mesmo problema. As consequências da violência perpetrada por parceiro íntimo são discutidas por Ellsberg et al. ${ }^{1}$, Campbell ${ }^{2}$, Pinheiro et al. $^{3} \mathrm{e}$ Abramsky et al. ${ }^{4}$. Enquanto Polman ${ }^{5}$, Ellsberg et al. ${ }^{1}$ e Abramsky et al. ${ }^{4}$ se dedicam a analisar as consequências para a saúde ou percepção da saúde, bem como de estudar outras formas de violência contra as mulheres, tais como: a violência cometida por homens sejam eles parentes, patrões, amigos ou estranhos. Outros autores investigaram o perfil da morbidade autodeclarada e concluíram que maiores níveis socioeconômicos conduzem a uma melhor autodeclaração da saúde $e^{6-9}$.

Nessa temática, o presente artigo se propõe a analisar como características socioeconômicas, demográficas, regionais e/ou comportamentais se relacionam com a autopercepção da saúde da mulher brasileira, com destaque para o efeito sobre a percepção do status de saúde (muito boa, boa, regular, ruim e muito ruim) a partir da ocorrência de violência sofrida pela mulher por pessoa conhecida, desconhecida ou ambos. Assim sendo, a hipótese a ser testada é que a violência sofrida pela mulher brasileira afeta a autopercepção de sua saúde. Para isto, utilizam-se as informações da Pesquisa Nacional de Saúde, PNS (2013), considerando as mulheres com idade entre 20 e 49 anos em duas amostras a partir da situação censitária (área urbana e rural).

Para atender aos objetivos propostos, o presente estudo é dividido em cinco seções, além desta introdução. A próxima aborda a relação entre violência e a saúde da mulher. Os aspectos metodológicos como fonte e tratamento dos dados e estratégia empírica compõem a seção três. Em seguida, são apresentadas a análise descritiva dos dados, bem como os resultados dos modelos estimados e, ainda, a análise e discussão dos resultados. E, por fim, são tecidas as considerações finais.

\section{A questão da violência e a saúde da mulher}

A violência doméstica, em especial a violência contra a mulher, é um fenômeno universal e persistente em diversas sociedades. Conforme Outlook $^{10}, 1 / 3$ das mulheres já sofreram alguma forma de violência ou abuso ao longo da vida. Comumente, o perpetrador da violência é uma pessoa conhecida da vítima, o que tende a reduzir o número de denúncias, sobretudo nas coletividades nas quais a violência contra a mulher é tida como um fenômeno normal ${ }^{11}$.

As ações de violência causam, em geral, efeitos diversos para a vida da mulher, independente da sua idade e condição social. Os referidos efeitos perpassam de sequelas físicas a traumas e demais consequências de ordem psicológicas, o que geralmente resulta em maior ônus para a sociedade como um todo, dado que as mulheres agredidas tendem a sofrer com baixa autoestima e muitas vezes problemas de saúde, que as impossibilitam total ou parcialmente de desenvolverem atividades laborativas.

McCauley et al. ${ }^{12}$ e Plichta e Falik ${ }^{13}$ argumentam que pessoas abusadas sexualmente são mais propensas ao alcoolismo, timidez, problemas de relacionamento, tendência suicida e depressão, dentre outros problemas de saúde. Existem relatos da existência de correlação entre ter sofrido violência e o desenvolvimento de doenças tais como alergias, dores pélvicas e irregularidade menstrual ${ }^{14}$.

Cabe destacar que o ciclo de violência contra a mulher pode ser iniciado mesmo antes do nascimento e se estender por toda a fase adulta. No período gestacional o ciclo da violência pode ocorrer principalmente por meio do aborto seletivo, ou seja, a partir de uma indicação formal de que bebês do sexo feminino sejam abortados.

Ademais, há de se considerar às ocorrências de abuso de crianças, casamentos precoces, bem como excessos sexuais e psicológicos. Em algumas regiões da África, por exemplo, as estatísticas oficiais indicam que casamento com crianças entre 7 e 8 anos é bastante comum e em partes da Nigéria, a idade média dos casamentos é de 11 anos $^{2}$.

Alguns destes fenômenos podem ser estendidos às adolescentes e mulheres em fase adulta, que também sofrem violência e muitas vezes são 
impedidas, ou inibidas, de procederem com denúncias.

De acordo com $\mathrm{WHO}^{15}$, a violência contra mulheres aumenta o risco de problemas de saúde. Todavia, a real dimensão das consequências é algo difícil de mensurar, contudo, a extensão da violência costumeiramente traz sequelas físicas e psíquicas. Os resultados encontrados para o $\mathrm{Ca}$ nadá, que tratam de diferentes aspectos de violência contra a mulher; um dos resultados apontou que $45 \%$ das mulheres casadas agredidas em assalto procuraram atendimento médico. $\mathrm{E}$, ain$\mathrm{da}$, que a violência durante a gravidez se constitui em um risco tanto para a saúde das mães quanto dos fetos.

Dentre as mulheres adultas vítimas de violência, as consequências possíveis podem ser o suicídio, problemas ginecológicos, gravidez indesejada, complicações na gravidez, aborto e a possibilidade de contágio com DSTs e/ou HIV/AIDS.

Com esteio nessa discussão, percebe-se a importância do acolhimento para mulheres que sofreram algum tipo de agressão, haja vista que essas mulheres, sobremaneira, buscam cuidados de saúde, sem fundamentalmente revelar o ensejo de suas lesões ou problemas.

Com base na literatura, cogita-se que tanto no meio urbano quanto no rural a violência majore a vulnerabilidade das mulheres a uma gama de problemas de saúde tanto no curto quanto no médio e longo prazo. Segundo Donnermeyer ${ }^{16}$ os relatos de violência são relativamente mais frequentes em áreas urbanas. No caso da violência sexual, esses relatos são duas vezes mais frequentes em áreas urbanas do que em áreas rurais, contudo o autor reporta que a incidência de estupro não seja divergente entre essas regiões censitárias.

Ademais, mesmo em áreas urbanas, ainda são pouco utilizados os itens necessários para promoção das provas periciais e a existência de residências com suporte para acolhimento de mulheres que sofreram violência.

Em áreas metropolitanas as mulheres são mais susceptíveis a violência cometida por estranhos, contudo, grande parte dos atos violentos sofridos pelas mulheres é advinda de pessoas conhecidas da vítima. No Brasil, de acordo com a PNS (2013), mais da metade das mulheres que residem em área rural e que sofreram violência foram agredidas por agentes conhecidos.

Apesar da subnotificação de relatos de violência mais preponderantes em áreas rurais, é mais provável que uma mulher rural identifique um agressor conhecido que uma mulher residente em área urbana ou metropolitana ${ }^{17}$.
Mesmo assim, ainda são muitos os entraves para uma correta identificação do fenômeno da violência contra a mulher, sobretudo no meio rural, dado que questões como isolamento geográfico, maiores chances de ausência de testemunhas, questões culturais e religiosas podem criar uma barreira que contribuem cada vez mais para que a violência contra a mulher seja um fenômeno ainda muito recorrente. Por este motivo fazse necessário um estudo desagregado por região censitária.

\section{Notas Metodológicas}

A PNS tem como objetivo produzir informações sobre a situação de saúde e estilo de vida da população brasileira e, ainda, visa obter informações sobre a atenção à saúde, no que se refere ao acesso e uso dos serviços de saúde, à continuidade dos cuidados e ao financiamento da assistência de saúde. Optou-se por utilizar informações da PNS (2013) para a consecução do objetivo.

Particularmente, constitui uma das poucas pesquisas de âmbito nacional que abrange os vinte e seis estados brasileiros mais o Distrito Federal, (configurada com o plano amostral), e considera elementos de saúde, tais como questões de doenças crônicas, tabagismo, aspectos de maternidade, enfermidades infantis. Contempla ainda informações sobre padrão alimentar de adultos e crianças. Em resumo, a pesquisa é subdividida em 23 diferentes módulos, especificados e aplicados por público entrevistado (mulheres idosas, crianças, pessoas com doenças crônicas etc). Alguns módulos foram coletados para todos os membros do domicílio, outros só para um indivíduo sorteado do domicílio com idade acima de 18 anos, tais como o módulo Estilo de vida.

A PNS contempla indivíduos de ambos os sexos e de todas as idades, inclusive crianças. Foram entrevistados 205.546 indivíduos de 0 (zero) a 109 anos de idade. Entretanto, por utilizar as informações do módulo estilo de vida, aplicado somente para maiores de 18 anos de idade, o presente estudo tem como população alvo, mulheres em idade fértil, particularmente as adultas com idade entre 20 e 49 anos (Deve-se salientar que biologicamente, o período fértil é definido após a primeira menstruação, contudo, o Ministério da Saúde postula como tempo fértil o intervalo dos 16 aos 49 anos de idade.).

Como indicador de saúde, utiliza-se o autorelato da saúde aferido a partir da seguinte indagação: Em geral, como o(a) sr(a) avalia a sua saúde? 
A qual possui cinco categorias de respostas, classificadas pelos entrevistados, quais sejam: muito bom, bom, regular, ruim e muito ruim.

Assim sendo, a autopercepção de saúde das mulheres brasileiras é descrita por uma escala de Likert crescente que assume os valores de $1 \mathrm{a}$ 5, para as seguintes classificações: Muito Bom, Bom, Regular, Ruim e Muito Ruim, respectivamente. Por isso, considera-se o uso do modelo logit ordenado e a partir do Teste de Brant ${ }^{18}$ podese inferir sobre a especificação do modelo entre: a) Modelo logit ordenado; b) Modelo logit ordenado generalizado; e, c) Modelo logit de chances parciais proporcionais.

A diferença entre os três modelos consiste, basicamente, na hipótese de que os efeitos das características (variáveis explicativas) se relacionam (ou não) a autoperceção de saúde (variável dependente) de forma fixa ao longo das $j$ diferentes categorias ${ }^{19-21}$.

Em relação às características das mulheres são consideradas informações demográficas e atributos natos (idade, idade ao quadrado, cor e estado civil); socioeconômicas (escolaridade, renda, se a mulher é pessoa de referência no domicílio e se tem plano de saúde); geográficas (se a unidade censitária é urbana ou rural e em qual macrorregião reside); estilo de vida, saúde e comportamento (se sofreu violência, se fuma ativa ou passivamente, níveis de peso corporal computados por meio do índice de massa corporal - IMC, se pratica esportes, autopercepção da saúde e se o consumo de álcool é considerado abusivo. De acordo com o Centro de Informações sobre saúde e Álcool (CISA), para adultos saudáveis em geral, o consumo pesado significa consumir mais do que a dose diária (4 doses para homens e 3 para mulheres) ou semanal indicadas como moderadas ( 14 doses para homens e 7 para mulheres), e às domiciliares (forma de abastecimento de água do domicílio e forma de escoadouro dos banheiros ou sanitários).

Utiliza-se como proxy de renda uma medida de estoque que emprega um conjunto de bens, serviços e características do domicílio para aferir sobre a renda do domicílio, a qual é construída conforme método proposto pela Associação Brasileira de Estudos da População ${ }^{22}$.

Para o cômputo dos níveis de peso, utiliza-se a sugestão da Organização Mundial da Saúde a partir do IMC, por isso, as mulheres com 18 e 19 anos foram excluídas desse estudo em virtude do fato das mesmas ainda estarem em fase de crescimento, assim como as gestantes, o que altera o cômputo das estatísticas de peso corporal. Em relação as categorias, são consideradas: Peso baixo, Peso normal, Sobrepeso, Pré-obesos e Obesos. Especificamente no tratamento da categoria obeso, são considerados três diferentes estágios de obesidades, quais sejam: Obeso I, Obeso II e Obesos III (obesidade mórbida). O Quadro 1 contempla as variáveis e suas descrições.

\section{Análise e discussão dos resultados}

Para aferir a relação entre as características socioeconômicas, demográficas, sociais e regionais e a autopercepção de saúde das mulheres em idade fértil no Brasil, são consideradas duas amostras, uma para as mulheres que residem em área urbana $(n=24.376)$ e outra para área rural $(n=$ 3.953). Essas amostras consideram apenas mulheres que responderam ao questionamento sobre sua autopercepção de saúde, a saber: Em geral, como o(a) sr(a) avalia a sua saúde?

Note pela Tabela 1 que 12,99\% das entrevistadas da área urbana autoavaliam sua saúde como muito boa. Contudo, a maioria $(52,04 \%)$ define seu próprio estado de saúde como bom. Proporcionalmente, as residentes em áreas rurais tendem a apresentar uma pior autopercepção de sua saúde, haja vista que apenas $6,25 \%$ avaliam a saúde como muito boa, enquanto $7,52 \%$ acham ruim.

Considerando a ocorrência de violência (Tabela 2), 96,34\% das entrevistadas que residem em áreas urbanas (relataram que) nunca sofreram violência de pessoa conhecida, enquanto que na área rural, o percentual foi de $97,07 \%$. E, por fim, $0,32 \%$ das entrevistadas já sofreram violência tanto de pessoas conhecidas quanto de desconhecidas, considerando as moradoras de zonas urbanas; e 0,09\% das residentes de áreas rurais relataram ter sofrido violência tanto de pessoas conhecidas como de desconhecidas.

Campbell ${ }^{2}$ ao revisar pesquisas sobre as sequelas na saúde mental e física das mulheres que sofreram violência perpetrada por parceiro intímo, concluiu que existem sequelas para as mulheres e filhos em mais de $10 \%$ dos casos. E, por isso, recomenda uma maior avaliação e intervenções para a violência de parceiros íntimos em ambientes de saúde.

Quanto à frequência com a qual a violência ocorre - considerando que a mesma tenha sido perpetrada por pessoa conhecida - note ainda pela Tabela 2 que a maior parte das entrevistadas reportou ter sofrida violência apenas uma vez. Pelos relatos, as mulheres que residem em área 
Quadro 1. Descrição das variáveis utilizadas para analisar a autoperceção de saúde da mulher brasileira.

\begin{tabular}{|c|c|}
\hline Variáveis & Descriçãa \\
\hline Autovaliação da saúde & 1 Muito Boa, 2 Boa, 3 Regular, 4 Ruim, 5 Muito Ruim \\
\hline \multicolumn{2}{|c|}{ Se a mulher já sofreu Violência } \\
\hline $\begin{array}{l}\text { Sofreu Violência de } \\
\text { pessoa conhecida }\end{array}$ & 1 se já sofreu violência de pessoa conhecida, 0 caso contrário \\
\hline $\begin{array}{l}\text { Sofreu Violência de } \\
\text { pessoa desconhecida }\end{array}$ & 1 se já sofreu violência de pessoa desconhecida, 0 caso contrário \\
\hline Sofreu Violência & 1 se já sofreu violência de pessoa conhecida e desconhecida, 0 caso contrário \\
\hline \multicolumn{2}{|c|}{ Demográficas e Atributos natos } \\
\hline Idade & Medida em anos (entre 20 e 49 anos) \\
\hline Idade $^{2}$ & A idade ao quadrado \\
\hline Branca & 1 se a mulher se autodeclara como Branca, 0 caso contrário \\
\hline Casada & 1 se a mulher for casada, 0 caso contrário \\
\hline \multicolumn{2}{|l|}{ Socioeconômicas } \\
\hline Analfabeto & 1 se o indivíduo for Analfabeto, 0 caso contrário \\
\hline Fundamental Incompleto & 1 se o indivíduo tem Ensino Fundamental incompleto, 0 caso contrário \\
\hline Fundamental Completo & 1 se o indivíduo tem Ensino Fundamental Completo, 0 caso contrário \\
\hline Médio Incompleto & 1 se o indivíduo tem Ensino Médio Incompleto, 0 caso contrário \\
\hline Médio Completo & 1 se o indivíduo tem Ensino Médio Completo, 0 caso contrário \\
\hline Superior Incompleto & 1 se o indivíduo tem Ensino Superior Incompleto, 0 caso contrário \\
\hline Superior Completo & 1 se o indivíduo tem Ensino Superior Completo, 0 caso contrário \\
\hline Renda* $^{*}$ & $\begin{array}{l}\text { Variável medida em reais ( } \mathrm{R} \$) \text {, construída a partir do estoque de bens domésticos } \\
\text { no domicílio }\end{array}$ \\
\hline Chefe do domicílio & 1 se a mulher é chefe de domicílio, 0 caso contrário \\
\hline Plano de Saúde & 1 se a mulher tem plano de saúde, 0 caso contrário \\
\hline \multicolumn{2}{|l|}{ Geográficas } \\
\hline Norte & 1 se o indivíduo reside na região Norte, 0 caso contrário \\
\hline Nordeste & 1 se o indivíduo reside na região Nordeste, 0 caso contrário \\
\hline Centro-Oeste & 1 se o indivíduo reside na região Centro-Oeste, 0 caso contrário \\
\hline Sul & 1 se o indivíduo reside na região Sul, 0 caso contrário \\
\hline Sudeste & 1 se o indivíduo reside na região Sudeste, 0 caso contrário \\
\hline \multicolumn{2}{|c|}{ Estilo de vida, Saúde e Comportamentais } \\
\hline Fuma & 1 Se o indivíduo é fumante, 0 caso contrário \\
\hline Fumante Passivo & 1 se tem algum fumante regular no domicílio, 0 caso contrário \\
\hline Bebida Alcoólica & 1 se a mulher consumiu mais que 3 doses em uma única ocasião, 0 caso contrário \\
\hline Baixo peso & 1 se o indivíduo tem IMC menor que $18,5,0$ caso contrário \\
\hline Peso normal & 1 se o indivíduo tem IMC entre 18,5 e $24,9,0$ caso contrário \\
\hline Pré-obeso & 1 se o indivíduo tem IMC entre 25,0 e 29,9, 0 caso contrário \\
\hline Obeso I & 1 se o indivíduo tem IMC maior que 30,0 caso contrário \\
\hline Doença crônica & 1 se já foi diagnosticada com alguma doença crônica, 0 caso contrário \\
\hline Pratica Esporte & 1 Se a mulher pratica algum esporte, 0 caso contrário \\
\hline \multicolumn{2}{|l|}{ Domiciliares } \\
\hline Abastecimento Água & $\begin{array}{l}1 \text { se a principal forma de abastecimento de água deste domicílio é rede geral de } \\
\text { distribuição, } 0 \text { caso contrário }\end{array}$ \\
\hline Rede de esgoto & $\begin{array}{l}1 \text { se a forma de escoadouro dos banheiros ou sanitários é por rede geral de esgoto } \\
\text { ou pluvial, } 0 \text { caso contrário }\end{array}$ \\
\hline Destino lixo & $\begin{array}{l}1 \text { se o lixo é coletado diretamente por serviço de limpeza e/ou caçamba de serviço } \\
\text { de limpeza, } 0 \text { caso contrário }\end{array}$ \\
\hline Energia Elétrica & 1 se a energia elétrica é fornecida por rede geral, 0 caso contrário \\
\hline
\end{tabular}

Fonte: Elaborado pelos autores a partir de dados da PNS (2013).

Notal: construída conforme metodologia proposta pela ABEP. Nota2: Utilizando à denominação proposta pela PNS (2013), o presente estudo considera como doenças crônicas todas as listadas no Módulo Q, doenças crônicas, a saber: Doença Renal, Artrite ou Reumatismo, Coluna/ Costas, Depressão, Diabetes, doença do coração, asma, bronquite crônica, câncer e Pressão Alta. Já como problemas de mobilidades estão incluídos: Dificuldade de Consertos domésticos ou Empurrar Mesa, Dificuldade Para Abaixar-se, Curva-se ou Ajoelhar-se, Dificuldade de Caminhar 100 Metros e Dificuldade de Comprar Alimentos, Roupas e Medicamento Sem Ajuda. 
urbana, proporcionalmente, sofrem mais violência de pessoas conhecidas que as mulheres residentes de áreas rurais (ou ao menos relatam mais o ocorrido).

Tabela 1. Autopercepção da saúde das mulheres brasileiras por área censitária, urbana e rural.

\begin{tabular}{|c|c|c|c|c|}
\hline \multirow{2}{*}{$\begin{array}{c}\text { Em geral, como } \\
\text { o(a) sr(a) avalia a } \\
\text { sua saúde? }\end{array}$} & \multicolumn{2}{|c|}{ Urbana } & \multicolumn{2}{|c|}{ Rural } \\
\hline & $\#$ & $\%$ & $\#$ & $\%$ \\
\hline Muito Boa & 3.166 & 12,99 & 247 & 6,25 \\
\hline Boa & 12.686 & 52,04 & 1.865 & 47,19 \\
\hline Regular & 7.020 & 28,80 & 1.484 & 37,55 \\
\hline Ruim & 1.173 & 4,81 & 297 & 7,52 \\
\hline Muito Ruim & 331 & 1,35 & 59 & 1,50 \\
\hline Total & 24.376 & 100,00 & 3.953 & 100,00 \\
\hline
\end{tabular}

Dentre aquelas que já sofreram violência, $7,16 \%$ delas relataram sofrer violência de pessoa conhecida quase diariamente, enquanto $19,14 \%$ sofreram de três a seis vezes nos últimos 12 meses. Na amostra rural, aproximadamente $2 \%$ das mulheres relataram ter sofrido violência quase diariamente e 18,23\% sofreram violência de pessoa conhecida duas vezes nos últimos doze meses.

Nessa mesma perspectiva, a maior parte das entrevistadas relatou que a violência mais grave sofrida nos últimos 12 meses, foi à violência física seguida pela violência psicológica, como se observa pela Tabela 3. Observe que nenhuma mulher que reside em área rural relatou ter sofrido violência sexual, enquanto na área urbana, 8 (oito) mulheres informaram que a violência mais grave que sofreram de pessoa conhecida nos últimos 12 meses foi violência sexual.

Quanto à violência mais grave atentada por pessoa desconhecida, as proporções são semelhantes aos relatos em caso de o agressor ser

Tabela 2. Ocorrência de violência perpetrada por agressor conhecido e desconhecido da vítima e Frequência de violência sofrida por pessoa conhecida nos últimos 12 meses.

\begin{tabular}{|c|c|c|c|c|}
\hline \multirow{2}{*}{$\begin{array}{l}\text { Nos últimos } 12 \text { meses a senhora sofreu violência ou agressão de pessoa } \\
\text { conhecida (como cônjuge, ex-cônjuge, pai/mãe, irmão, patrão ou outro } \\
\text { parente)? }\end{array}$} & \multicolumn{2}{|c|}{ Urbano } & \multicolumn{2}{|c|}{ Rural } \\
\hline & \# & $\%$ & \# & $\%$ \\
\hline Não & 23.484 & 96,34 & 3.837 & 97,07 \\
\hline Sim & 892 & 3,66 & 116 & 2,93 \\
\hline Total & 24.376 & 100.00 & 3.953 & 100,00 \\
\hline \multirow{2}{*}{$\begin{array}{l}\text { Nos últimos } 12 \text { meses a senhora sofreu violência ou agressão de pessoa } \\
\text { desconhecida (bandido, policial, assaltante etc)? }\end{array}$} & \multicolumn{2}{|c|}{ Urbano } & \multicolumn{2}{|c|}{ Rural } \\
\hline & \# & $\%$ & \# & $\%$ \\
\hline Não & 23.508 & 96,44 & 3.897 & 98,59 \\
\hline $\operatorname{Sim}$ & 868 & 3,56 & 56 & 1,41 \\
\hline Total & 24.376 & 100,00 & 3.953 & 100,00 \\
\hline \multirow{2}{*}{$\begin{array}{l}\text { Nos últimos } 12 \text { meses a senhora sofreu violência ou agressão de pessoa } \\
\text { conhecida e desconhecida? }\end{array}$} & \multicolumn{2}{|c|}{ Urbano } & \multicolumn{2}{|c|}{ Rural } \\
\hline & $\#$ & $\%$ & $\#$ & $\%$ \\
\hline Não & 24.298 & 99,68 & 3.949 & 99,91 \\
\hline Sim & 78 & 0,32 & 4 & 0,09 \\
\hline Total & 24.376 & 100,00 & 3.953 & 100,00 \\
\hline \multirow{2}{*}{$\begin{array}{l}\text { Nos últimos } 12 \text { meses, com que frequência sofreu alguma violência de pessoa } \\
\text { conhecida? }\end{array}$} & \multicolumn{2}{|c|}{ Urbana } & \multicolumn{2}{|c|}{ Rural } \\
\hline & $\#$ & $\%$ & $\#$ & $\%$ \\
\hline 1. Uma vez & 530 & 47,41 & 119 & 58,62 \\
\hline 2. Duas vezes & 167 & 14,94 & 37 & 18,23 \\
\hline 3. De três a seis vezes & 214 & 19,14 & 24 & 11,82 \\
\hline 4. De sete a menos de 12 vezes & 45 & 4,03 & 9 & 4,43 \\
\hline 5. Pelo menos uma vez por mês & 42 & 3,76 & 4 & 1,97 \\
\hline 6. Pelo menos uma vez por semana & 40 & 3,58 & 6 & 2,96 \\
\hline 7. Quase diariamente & 80 & 7,16 & 4 & 1,97 \\
\hline Total & 1.118 & 100,00 & 203 & 100,00 \\
\hline
\end{tabular}

Fonte: Elaborado pelos autores a partir de dados da PNS (2013).

Nota: \# e \% denotam as frequências absoluta e relativa, respectivamente. 
Tabela 3. Classificação do tipo de violência sofrida pelas mulheres e Frequência por tipo de violência e ameaça mais grave relatada pela mulher nos últimos 12 meses

\begin{tabular}{|c|c|c|c|c|c|}
\hline \multirow{7}{*}{$\begin{array}{l}\text { Pensando na } \\
\text { violência mais grave } \\
\text { que o(a) sr(a) sofreu } \\
\text { de pessoa conhecida } \\
\text { nos últimos } 12 \text { meses, } \\
\text { que tipo de violência } \\
\text { o(a) sr(a) sofreu? }\end{array}$} & Área & \multicolumn{2}{|c|}{ Urbana } & \multicolumn{2}{|c|}{ Rural } \\
\hline & Tipo de violência & $\#$ & $\%$ & $\#$ & $\%$ \\
\hline & Física & 495 & 44,28 & 94 & 46,31 \\
\hline & Sexual & 8 & 0,72 & - & - \\
\hline & Psicológica & 539 & 48,21 & 95 & 46,80 \\
\hline & Outra & 76 & 6,80 & 14 & 6,90 \\
\hline & Total & 1.118 & 100,00 & 203 & 100,00 \\
\hline \multirow{7}{*}{$\begin{array}{l}\text { Pensando na } \\
\text { violência mais } \\
\text { grave que o(a) sr(a) } \\
\text { sofreu de pessoa } \\
\text { desconhecida nos } \\
\text { últimos } 12 \text { meses, que } \\
\text { tipo de violência o(a) } \\
\text { sr(a) sofreu? }\end{array}$} & Área & \multicolumn{2}{|c|}{ Urbana } & \multicolumn{2}{|c|}{ Rural } \\
\hline & Tipo de violência & $\#$ & $\%$ & $\#$ & $\%$ \\
\hline & Física & 631 & 42,78 & 59 & 41,26 \\
\hline & Sexual & 9 & 0,61 & 2 & 1,40 \\
\hline & Psicológica & 736 & 49,90 & 67 & 46,85 \\
\hline & Outra & 99 & 6,71 & 15 & 10,49 \\
\hline & Total & 1.475 & 100,00 & 143 & 100,00 \\
\hline \multirow{12}{*}{$\begin{array}{l}\text { Pensando na } \\
\text { violência mais grave } \\
\text { que o(a) sr(a) sofreu } \\
\text { de pessoa conhecida } \\
\text { nos últimos } 12 \text { meses, } \\
\text { como o(a) sr(a) foi } \\
\text { ameaçado(a) ou } \\
\text { ferido(a)? }\end{array}$} & Área & \multicolumn{2}{|c|}{ Urbana } & \multicolumn{2}{|c|}{ Rural } \\
\hline & Frequência: violência e ameaça & \# & $\%$ & $\#$ & $\%$ \\
\hline & $\begin{array}{l}\text { 1. Com força corporal/espancamento (tapa, murro, } \\
\text { beliscão, empurrão). }\end{array}$ & 396 & 35,42 & 72 & 35,47 \\
\hline & 2. Com arma de fogo (revólver, escopeta, pistola). & 19 & 1,70 & 2 & 0,99 \\
\hline & $\begin{array}{l}\text { 3. Com objeto pérfuro-cortante (faca, navalha, punhal, } \\
\text { tesoura). }\end{array}$ & 45 & 4,03 & 15 & 7,39 \\
\hline & $\begin{array}{l}\text { 4. Com objeto contundente (pau, cassetete, barra de } \\
\text { ferro, pedra). }\end{array}$ & 31 & 2,77 & 2 & 0,99 \\
\hline & 5. Com arremesso de substância/objeto quente. & 3 & 0,27 & - & \\
\hline & 6. Com lançamento de objetos & 19 & 1,70 & 3 & 1,48 \\
\hline & 7. Com envenenamento. & - & - & 1 & 0,49 \\
\hline & $\begin{array}{l}\text { 8. Por meio de palavras ofensivas, xingamentos ou } \\
\text { palavrões. }\end{array}$ & 582 & 52,06 & 105 & 51,72 \\
\hline & 9. Outro: & 23 & 2,06 & 3 & 1,48 \\
\hline & Total & 1.118 & 100,0 & 203 & 100,0 \\
\hline
\end{tabular}

Fonte: Elaborado pelos autores a partir de dados da PNS (2013).

Nota: \# e \% denotam as frequências absoluta e relativa, respectivamente.

conhecido da vítima. Ou seja, os atos mais frequentes são de violência física ou psicológica. No tocante à violência do tipo sexual (com agressor desconhecido), a mesma foi mais reportada dentre as entrevistadas do meio rural.

Analisando a violência e ameaça mais grave sofrida por pessoa conhecida nos últimos 12 meses, verifica-se que tanto no meio urbano quanto no rural, aproximadamente $52 \%$ das mulheres foram vítimas de palavras ofensivas, xingamentos ou palavrões. Em segundo lugar, (35\% das mulheres) o tipo de violência mais grave foi com força corporal/espancamento (tapa, murro, beliscão, empurrão).

Analisando os efeitos marginais expostos na Tabela 4, estimados a partir dos modelos logit ordenados, verifica-se que as mulheres que relata- ram ter sofrido violência nos últimos doze meses não apresenta diferença em termos de autoperceção de saúde em relação as que não sofreram violência. As mulheres que sofreram violência perpetrada por pessoa conhecida, possuem menor chance de autoperceber o estado de saúde como muito bom; além de apresentarem maior chance de auto relatar à saúde como regular. Em relação as que residem em área rural, não se observou nenhuma significância estatística.

Quanto à violência praticada por pessoa desconhecida, não se observa diferença na autopercepção de saúde entre as mulheres que sofreram e as que não sofreram violência e residem no meio urbano. Por outro lado, as mulheres que residem em área rural, possuem menor chance de autodeclarar o estado de saúde como muito bom ou 
Tabela 4. Efeitos marginais das características demográficas, econômicas, sociais e regionais sobre autopercepção da saúde das mulheres brasileiras, urbano e rural, Brasil, 2013.

\begin{tabular}{|c|c|c|c|c|c|c|c|c|c|c|}
\hline \multirow{2}{*}{$\begin{array}{c}\text { Modelos } \\
\text { Variáveis } \\
\text { explicativas }\end{array}$} & \multicolumn{5}{|c|}{ Urbano } & \multicolumn{5}{|c|}{ Rural } \\
\hline & $\begin{array}{c}\text { Muito } \\
\text { boa }\end{array}$ & Boa & Regular & Ruim & $\begin{array}{l}\text { Muito } \\
\text { Ruim }\end{array}$ & $\begin{array}{c}\text { Muito } \\
\text { boa }\end{array}$ & Boa & Regular & Ruim & $\begin{array}{l}\text { Muito } \\
\text { Ruim }\end{array}$ \\
\hline $\begin{array}{l}\text { Sofreu } \\
\text { Violência } \\
\text { de pessoa } \\
\text { conhecida }\end{array}$ & $\begin{array}{r}-0,0421 \\
(0,0100)\end{array}$ & $\begin{array}{r}-0,0254 \\
(0,1250)\end{array}$ & $\begin{array}{r}0,0591 \\
(0,0380)\end{array}$ & $\begin{array}{r}0,0072 \\
(0,0590)\end{array}$ & $\begin{array}{r}0,0012 \\
(0,0830)\end{array}$ & $\begin{array}{r}0,0198 \\
(0,6410)\end{array}$ & $\begin{array}{r}0,0352 \\
(0,5580)\end{array}$ & $\begin{array}{r}-0,0503 \\
(0,5930)\end{array}$ & $\begin{array}{r}-0,0046 \\
(0,5700)\end{array}$ & $\begin{array}{r}0,0022 \\
(0,1650)\end{array}$ \\
\hline $\begin{array}{l}\text { Sofreu } \\
\text { Violência } \\
\text { de pessoa } \\
\text { desconhecida }\end{array}$ & $\begin{array}{r}-0,0190 \\
(0,3650)\end{array}$ & $\begin{array}{r}-0,0079 \\
(0,5010)\end{array}$ & $\begin{array}{r}0,0237 \\
(0,4090)\end{array}$ & $\begin{array}{r}0,0027 \\
(0,4240)\end{array}$ & $\begin{array}{r}0,0005 \\
(0,4350)\end{array}$ & $\begin{array}{r}-0,0579 \\
(0,0000)\end{array}$ & $\begin{array}{r}-0,2906 \\
(0,0220)\end{array}$ & $\begin{array}{r}0,2908 \\
(0,0040)\end{array}$ & $\begin{array}{r}0,0577 \\
(0,1760)\end{array}$ & $\begin{array}{r}-0,0008 \\
(0,6460)\end{array}$ \\
\hline $\begin{array}{l}\text { Sofreu } \\
\text { Violência }\end{array}$ & $\begin{array}{r}-0,0551 \\
(0,1800)\end{array}$ & $\begin{array}{r}-0,0443 \\
(0,4770)\end{array}$ & $\begin{array}{r}0,0863 \\
(0,3270)\end{array}$ & $\begin{array}{r}0,0111 \\
(0,3930)\end{array}$ & $\begin{array}{r}0,0019 \\
(0,4150)\end{array}$ & $\begin{array}{r}0,0297 \\
(0,7920)\end{array}$ & $\begin{array}{r}0,0456 \\
(0,6900)\end{array}$ & $\begin{array}{r}-0,0692 \\
(0,7420)\end{array}$ & $\begin{array}{r}-0,0061 \\
(0,7150)\end{array}$ & $\begin{array}{r}0,0001 \\
(0,6960)\end{array}$ \\
\hline Idade & & $\begin{array}{r}-0,0005 \\
(0,6540)\end{array}$ & $\begin{array}{r}0,0021 \\
(0,6530)\end{array}$ & $\begin{array}{r}0,0002 \\
(0,6530)\end{array}$ & $\begin{array}{r}0,0000 \\
(0,6550)\end{array}$ & $\begin{array}{r}0,0118 \\
(0,1160)\end{array}$ & $\begin{array}{r}0,0258 \\
(0,1270)\end{array}$ & $\begin{array}{r}-0,0342 \\
(0,1190)\end{array}$ & & \\
\hline Idade $^{2}$ & & $\begin{array}{r}0,0000 \\
(0,9510)\end{array}$ & $\begin{array}{r}0,0000 \\
(0,9510)\end{array}$ & $\begin{array}{r}0,0000 \\
(0,9510)\end{array}$ & & & & $\begin{array}{r}0,0006 \\
(0,0810)\end{array}$ & $\begin{array}{r}0,0001 \\
(0,1030)\end{array}$ & $\begin{array}{r}0,0000 \\
(0,1700)\end{array}$ \\
\hline Branca & $\begin{array}{r}0,0278 \\
(0,0070)\end{array}$ & $\begin{array}{r}0,0071 \\
(0,0090)\end{array}$ & $\begin{array}{r}-0,0309 \\
(0,0060)\end{array}$ & $\begin{array}{r}-0,0034 \\
(0,0070)\end{array}$ & $\begin{array}{r}-0,0006 \\
(0,0240)\end{array}$ & $\begin{array}{r}0,0038 \\
(0,8580)\end{array}$ & $\begin{array}{r}0,0081 \\
(0,8550)\end{array}$ & $\begin{array}{r}-0,0109 \\
(0,8560)\end{array}$ & & $\begin{array}{r}-0,0007 \\
(0,1060)\end{array}$ \\
\hline Casada & $\begin{array}{r}0,0114 \\
(0,2880)\end{array}$ & $\begin{array}{r}0,0029 \\
(0,2330)\end{array}$ & $\begin{array}{r}-0,0126 \\
(0,2750)\end{array}$ & $\begin{array}{r}-0,0014 \\
(0,2740)\end{array}$ & $\begin{array}{r}-0,0002 \\
(0,2940)\end{array}$ & $\begin{array}{r}-0,0096 \\
(0,5870)\end{array}$ & $\begin{array}{r}-0,0225 \\
(0,6070)\end{array}$ & $\begin{array}{r}0,0292 \\
(0,6000)\end{array}$ & $\begin{array}{r}0,0029 \\
(0,6140)\end{array}$ & $\begin{array}{r}0,0000 \\
(0,9300)\end{array}$ \\
\hline $\begin{array}{l}\text { Fundamental } \\
\text { Incompleto }\end{array}$ & $\begin{array}{r}-0,0096 \\
(0,6280)\end{array}$ & $\begin{array}{r}-0,0032 \\
(0,6740)\end{array}$ & $\begin{array}{r}0,0113 \\
(0,6400)\end{array}$ & $\begin{array}{r}0,0013 \\
(0,6440)\end{array}$ & $\begin{array}{r}0,0002 \\
(0,6490)\end{array}$ & $\begin{array}{r}0,0535 \\
(0,1330)\end{array}$ & $\begin{array}{r}0,0879 \\
(0,0320)\end{array}$ & $\begin{array}{c}-0,1295 \\
(0,0570)\end{array}$ & $\begin{array}{c}-0,0119 \\
(0,0850)\end{array}$ & $\begin{array}{r}-0,0001 \\
(0,7660)\end{array}$ \\
\hline $\begin{array}{l}\text { Fundamental } \\
\text { Completo }\end{array}$ & $\begin{array}{r}0,0367 \\
(0,1440)\end{array}$ & $\begin{array}{r}0,0043 \\
(0,0250)\end{array}$ & $\begin{array}{r}-0,0365 \\
(0,0930)\end{array}$ & & & $\begin{array}{r}0,0738 \\
(0,1730)\end{array}$ & $\begin{array}{r}0,0831 \\
(0,0020)\end{array}$ & & & \\
\hline $\begin{array}{l}\text { Médio } \\
\text { Incompleto }\end{array}$ & $\begin{array}{r}0,0358 \\
(0,2080)\end{array}$ & $\begin{array}{r}0,0039 \\
(0,0730)\end{array}$ & $\begin{array}{r}-0,0353 \\
(0,1440)\end{array}$ & $\begin{array}{r}-0,0038 \\
(0,1350)\end{array}$ & $\begin{array}{r}-0,0006 \\
(0,1480)\end{array}$ & $\begin{array}{r}0,0746 \\
(0,2330)\end{array}$ & $\begin{array}{r}0,0802 \\
(0,0010)\end{array}$ & $\begin{array}{r}-0,1428 \\
(0,0590)\end{array}$ & $\begin{array}{r}-0,0120 \\
(0,0590)\end{array}$ & $\begin{array}{r}-0,0005 \\
(0,4720)\end{array}$ \\
\hline $\begin{array}{l}\text { Médio } \\
\text { Completo }\end{array}$ & $\begin{array}{r}0,0627 \\
(0,0040)\end{array}$ & $\begin{array}{r}0,0099 \\
(0,0010)\end{array}$ & & & & $\begin{array}{r}0,1066 \\
(0,0420)\end{array}$ & $\begin{array}{r}0,1174 \\
(0,0000)\end{array}$ & & & \\
\hline $\begin{array}{l}\text { Superior } \\
\text { Incompleto }\end{array}$ & $\begin{array}{r}0,1112 \\
(0,0020)\end{array}$ & & & & & $\begin{array}{r}0,1359 \\
(0,1160)\end{array}$ & $\begin{array}{r}0,0725 \\
(0,0300)\end{array}$ & & & \\
\hline $\begin{array}{l}\text { Superior } \\
\text { Completo }\end{array}$ & $\begin{array}{r}0,1438 \\
(0,0000)\end{array}$ & $\begin{array}{r}-0,0127 \\
(0,3130)\end{array}$ & $\begin{array}{r}-0,1167 \\
(0,0000)\end{array}$ & $\begin{array}{r}-0,0123 \\
(0,0000)\end{array}$ & $\begin{array}{r}-0,0021 \\
(0,0010)\end{array}$ & $\begin{array}{r}0,1121 \\
(0,1130)\end{array}$ & $\begin{array}{r}0,0818 \\
(0,0000)\end{array}$ & $\begin{array}{r}-0,1795 \\
(0,0040)\end{array}$ & $\begin{array}{r}-0,0144 \\
(0,0140)\end{array}$ & $\begin{array}{r}-0,0 \\
(0,41\end{array}$ \\
\hline Renda & $\begin{array}{r}0,0000 \\
(0,0000)\end{array}$ & $\begin{array}{r}0,0000 \\
(0,0030)\end{array}$ & $\begin{array}{r}0,0000 \\
(0,0000)\end{array}$ & $\begin{array}{r}0,0000 \\
(0,0010)\end{array}$ & $\begin{array}{r}0,0000 \\
(0,0080)\end{array}$ & $\begin{array}{r}0,0000 \\
(0,8640)\end{array}$ & $\begin{array}{r}0,0000 \\
(0,8640)\end{array}$ & $\begin{array}{r}0,0000 \\
(0,8640)\end{array}$ & $\begin{array}{r}0,0000 \\
(0,8650)\end{array}$ & $\begin{array}{r}0,0000 \\
(0,4320)\end{array}$ \\
\hline $\begin{array}{l}\text { Pessoa de ref. } \\
\text { do Domicilio }\end{array}$ & $\begin{array}{r}0,0331 \\
(0,0000)\end{array}$ & $\begin{array}{r}0,0098 \\
(0,0020)\end{array}$ & $\begin{array}{r}-0,0379 \\
(0,0000)\end{array}$ & $\begin{array}{r}-0,0043 \\
(0,0010)\end{array}$ & $\begin{array}{r}-0,0007 \\
(0,0060)\end{array}$ & $\begin{array}{r}-0,0043 \\
(0,8040)\end{array}$ & $\begin{array}{r}-0,0095 \\
(0,8060)\end{array}$ & $\begin{array}{r}0,0126 \\
(0,8050)\end{array}$ & $\begin{array}{r}0,0012 \\
(0,8080)\end{array}$ & $\begin{array}{r}-0,0006 \\
(0,1850)\end{array}$ \\
\hline $\begin{array}{l}\text { Plano de } \\
\text { Saúde }\end{array}$ & $\begin{array}{r}0,0510 \\
(0,0000)\end{array}$ & $\begin{array}{r}0,0100 \\
(0,0000)\end{array}$ & $\begin{array}{r}-0,0541 \\
(0,0000)\end{array}$ & $\begin{array}{r}-0,0060 \\
(0,0000)\end{array}$ & $\begin{array}{r}-0,0010 \\
(0,0030)\end{array}$ & $\begin{array}{r}0,0451 \\
(0,2160)\end{array}$ & $\begin{array}{r}0,0665 \\
(0,0600)\end{array}$ & $\begin{array}{r}-0,1025 \\
(0,1130)\end{array}$ & $\begin{array}{r}-0,0091 \\
(0,1180)\end{array}$ & $\begin{array}{r}-0,0013 \\
(0,0410)\end{array}$ \\
\hline Norte & $\begin{array}{r}-0,0554 \\
(0,0000)\end{array}$ & $\begin{array}{r}-0,0329 \\
(0,0050)\end{array}$ & $\begin{array}{r}0,0773 \\
(0,0000)\end{array}$ & $\begin{array}{r}0,0094 \\
(0,0010)\end{array}$ & $\begin{array}{r}0,0016 \\
(0,0080)\end{array}$ & $\begin{array}{r}-0,0499 \\
(0,0050)\end{array}$ & $\begin{array}{r}-0,1596 \\
(0,0250)\end{array}$ & $\begin{array}{r}0,1862 \\
(0,0130)\end{array}$ & $\begin{array}{r}0,0233 \\
(0,0850)\end{array}$ & $\begin{array}{r}0,0012 \\
(0,0610)\end{array}$ \\
\hline Nordeste & $\begin{array}{r}-0,0614 \\
(0,0000)\end{array}$ & $\begin{array}{r}-0,0306 \\
(0,0000)\end{array}$ & $\begin{array}{r}0,0807 \\
(0,0000)\end{array}$ & $\begin{array}{r}0,0096 \\
(0,0000)\end{array}$ & $\begin{array}{r}0,0017 \\
(0,0020)\end{array}$ & $\begin{array}{r}-0,0456 \\
(0,0330)\end{array}$ & $\begin{array}{r}-0,1123 \\
(0,0400)\end{array}$ & $\begin{array}{r}0,1427 \\
(0,0300)\end{array}$ & $\begin{array}{r}0,0153 \\
(0,0970)\end{array}$ & $\begin{array}{r}-0,0010 \\
(0,1570)\end{array}$ \\
\hline Centro-Oeste & $\begin{array}{r}-0,0145 \\
(0,2860)\end{array}$ & $\begin{array}{r}-0,0053 \\
(0,3820)\end{array}$ & $\begin{array}{r}0,0175 \\
(0,3110)\end{array}$ & $\begin{array}{r}0,0020 \\
(0,3250)\end{array}$ & $\begin{array}{r}0,0003 \\
(0,3330)\end{array}$ & $\begin{array}{r}-0,0191 \\
(0,4630)\end{array}$ & $\begin{array}{r}-0,0512 \\
(0,5450)\end{array}$ & $\begin{array}{r}0,0635 \\
(0,5200)\end{array}$ & $\begin{array}{r}0,0068 \\
(0,5630)\end{array}$ & $\begin{array}{r}-0,0005 \\
(0,3570)\end{array}$ \\
\hline Sul & $\begin{array}{r}-0,0013 \\
(0,9280)\end{array}$ & $\begin{array}{r}-0,0004 \\
(0,9290)\end{array}$ & $\begin{array}{r}0,0015 \\
(0,9280)\end{array}$ & $\begin{array}{r}0,0002 \\
(0,9280)\end{array}$ & $\begin{array}{r}0,0000 \\
(0,9280)\end{array}$ & $\begin{array}{r}0,0129 \\
(0,7440)\end{array}$ & $\begin{array}{r}0,0248 \\
(0,7060)\end{array}$ & $\begin{array}{r}-0,0345 \\
(0,7210)\end{array}$ & $\begin{array}{r}-0,0032 \\
(0,7070)\end{array}$ & $\begin{array}{r}-0,0003 \\
(0,4360)\end{array}$ \\
\hline $\begin{array}{l}\text { Abastecimento } \\
\text { Água }\end{array}$ & $\begin{array}{r}0,0244 \\
(0,0820)\end{array}$ & $\begin{array}{r}0,0109 \\
(0,2150)\end{array}$ & $\begin{array}{r}-0,0310 \\
(0,1190)\end{array}$ & $\begin{array}{r}-0,0036 \\
(0,1360)\end{array}$ & $\begin{array}{l}-0,0006 \\
(0,1640)\end{array}$ & $\begin{array}{r}-0,0207 \\
(0,2590)\end{array}$ & $\begin{array}{r}-0,0485 \\
(0,2770)\end{array}$ & $\begin{array}{r}0,0628 \\
(0,2680)\end{array}$ & $\begin{array}{r}0,0064 \\
(0,2870)\end{array}$ & $\begin{array}{r}-0,0011 \\
(0,0940)\end{array}$ \\
\hline $\begin{array}{l}\text { Rede de } \\
\text { esgoto }\end{array}$ & $\begin{array}{r}-0,0001 \\
(0,9920)\end{array}$ & $\begin{array}{r}0,0000 \\
(0,9920)\end{array}$ & $\begin{array}{r}0,0001 \\
(0,9920)\end{array}$ & $\begin{array}{r}0,0000 \\
(0,9920)\end{array}$ & $\begin{array}{r}0,0000 \\
(0,9920)\end{array}$ & $\begin{array}{c}-0,0056 \\
(0,8530)\end{array}$ & $\begin{array}{r}-0,0131 \\
(0,8610)\end{array}$ & $\begin{array}{r}0,0171 \\
(0,8590)\end{array}$ & $\begin{array}{r}0,0017 \\
(0,8620)\end{array}$ & $\begin{array}{r}0,0001 \\
(0,6050)\end{array}$ \\
\hline Coleta de lixo & $\begin{array}{r}0,0014 \\
(0,8830) \\
\end{array}$ & $\begin{array}{r}0,0004 \\
(0,8840) \\
\end{array}$ & $\begin{array}{r}-0,0016 \\
(0,8830) \\
\end{array}$ & $\begin{array}{r}-0,0002 \\
(0,8840) \\
\end{array}$ & $\begin{array}{r}0,0000 \\
(0,8830) \\
\end{array}$ & $\begin{array}{r}-0,0140 \\
(0,1200) \\
\end{array}$ & $\begin{array}{r}-0,0309 \\
(0,1160) \\
\end{array}$ & $\begin{array}{r}0,0409 \\
(0,1120) \\
\end{array}$ & $\begin{array}{r}0,0040 \\
(0,1350) \\
\end{array}$ & $\begin{array}{r}-0,0003 \\
(0,6540) \\
\end{array}$ \\
\hline
\end{tabular}


Tabela 4. Efeitos marginais das características demográficas, econômicas, sociais e regionais sobre autopercepção da saúde das mulheres brasileiras, urbano e rural, Brasil, 2013.

\begin{tabular}{lrrrrrrrrrrr}
\hline \multicolumn{1}{c}{ Modelos } & \multicolumn{3}{c}{ Urbano } & \multicolumn{1}{c}{ Rural } \\
\hline $\begin{array}{l}\text { Variáveis } \\
\text { explicativas }\end{array}$ & $\begin{array}{c}\text { Muito } \\
\text { boa }\end{array}$ & Boa & Regular & Ruim & $\begin{array}{c}\text { Muito } \\
\text { Ruim }\end{array}$ & $\begin{array}{c}\text { Muito } \\
\text { boa }\end{array}$ & Boa & Regular & Ruim & $\begin{array}{c}\text { Muito } \\
\text { Ruim }\end{array}$ \\
\hline Energia & 0,0395 & 0,0247 & $-0,0561$ & $-0,0069$ & $-0,0012$ & $-0,0275$ & $-0,0436$ & 0,0653 & 0,0058 & $-0,0009$ \\
elétrica & $(0,8990)$ & $(0,9400)$ & $(0,9190)$ & $(0,9260)$ & $(0,9260)$ & $(0,7840)$ & $(0,6870)$ & $(0,7350)$ & $(0,7110)$ & $(0,3200)$ \\
Fuma & 0,0156 & 0,0036 & $-0,0170$ & $-0,0019$ & $-0,0003$ & 0,0406 & 0,0658 & $-0,0976$ & $-0,0089$ & 0,0002 \\
& $(0,2350)$ & $(0,1330)$ & $(0,2130)$ & $(0,2120)$ & $(0,2260)$ & $(0,2120)$ & $(0,0750)$ & $(0,1210)$ & $(0,1170)$ & $(0,5950)$ \\
Fumante & $-0,0395$ & $-0,0174$ & 0,0501 & 0,0058 & 0,0010 & $-0,0399$ & $-0,1100$ & 0,1347 & 0,0151 & 0,0002 \\
passiva & $(0,0000)$ & $(0,0080)$ & $(0,0000)$ & $(0,0020)$ & $(0,0120)$ & $(0,0180)$ & $(0,0350)$ & $(0,0230)$ & $(0,0860)$ & $(0,8710)$ \\
Bebida & 0,0151 & 0,0045 & $-0,0173$ & $-0,0019$ & $-0,0003$ & $-0,0202$ & $-0,0441$ & 0,0585 & 0,0058 & $-0,0005$ \\
Alcoólica & $(0,0870)$ & $(0,1070)$ & $(0,0890)$ & $(0,0930)$ & $(0,1090)$ & $(0,2180)$ & $(0,2420)$ & $(0,2280)$ & $(0,2750)$ & $(0,1990)$ \\
Pratica & 0,0386 & 0,0088 & $-0,0420$ & $-0,0047$ & $-0,0008$ & 0,0138 & 0,0277 & $-0,0379$ & $-0,0036$ & 0,0087 \\
Esporte & $(0,0000)$ & $(0,0010)$ & $(0,0000)$ & $(0,0000)$ & $(0,0060)$ & $(0,5500)$ & $(0,5150)$ & $(0,5260)$ & $(0,5280)$ & $(0,0310)$ \\
Doença & $-0,1172$ & $-0,1577$ & 0,2315 & 0,0368 & 0,0065 & $-0,0684$ & $-0,3311$ & 0,3305 & 0,0690 & 0,0003 \\
crônica & $(0,0000)$ & $(0,0000)$ & $(0,0000)$ & $(0,0000)$ & $(0,0000)$ & $(0,0000)$ & $(0,0000)$ & $(0,0000)$ & $(0,0600)$ & $(0,5060)$ \\
Baixo peso & 0,0361 & 0,0033 & $-0,0350$ & $-0,0037$ & $-0,0006$ & 0,1305 & 0,0666 & $-0,1831$ & $-0,0141$ & $-0,0004$ \\
& $(0,3450)$ & $(0,3380)$ & $(0,2670)$ & $(0,2480)$ & $(0,2660)$ & $(0,2620)$ & $(0,0890)$ & $(0,0230)$ & $(0,0240)$ & $(0,2800)$ \\
Peso Normal & 0,0411 & 0,0094 & $-0,0447$ & $-0,0050$ & $-0,0008$ & $-0,0011$ & $-0,0024$ & 0,0032 & 0,0003 & 0,0002 \\
& $(0,0000)$ & $(0,0000)$ & $(0,0000)$ & $(0,0000)$ & $(0,0040)$ & $(0,9480)$ & $(0,9480)$ & $(0,9480)$ & $(0,9480)$ & $(0,9480)$ \\
Observações & & & & & 24.376 & & & & & & 3.953 \\
\hline
\end{tabular}

Fonte: Elaborado pelos autores a partir de dados da PNS (2013).

Nota 1: P-valor entre parênteses. Nota 2: categorias de referência: Raça: Não branca; Estado civil: Não casada; Escolaridade: Analfabeto;

Macrorregião: Sudeste; Sit. Violência: Nunca sofreu violência e Medida antropométrica: Obesas (independentemente do nível de obesidade).

bom, e maior probabilidade de declarar o estado de saúde como regular.

As mulheres que residem na área rural, e que sofreram violência de pessoa desconhecida possuem menor probabilidade de perceberem a saúde como boa ou muito boa. A violência realizada por pessoa conhecida apresenta efeito significativo sobre autopercepção de saúde da mulher. Especificamente, sofrer violência física de pessoa conhecida reduz à probabilidade de que a mulher julgue sua saúde como boa ou muito boa, associando-se ainda com a probabilidade de que a saúde seja auto avaliada como ruim ou muito ruim. As mulheres que sofreram violência de desconhecidos - habitantes em áreas urbanas ou rurais - também apresentam piores percepções de sua saúde.

Os resultados encontrados no presente estudo indicam que apenas para as mulheres residentes em áreas urbanas, sofrer violência de agente conhecido reduz a probabilidade de reportar sua saúde como muito boa, entretanto, os demais resultados não são conclusivos. Assim sendo, notase à necessidade de novas pesquisas com dados mais direcionados, haja vista que se tem no presente estudo, provável subnotificação de relatos de violência (principalmente nas áreas rurais).
Adicionalmente, verifica-se que algumas mulheres atribuem o comportamento violento (em especial de agressores do sexo masculino) a fatores externos, tais como, o alcoolismo, o uso de entorpecentes ilícitos, problemas no trabalho, etc. $^{23}$. Ou seja, resultados inconclusivos podem ser justificados pelo fato das mulheres desresponsabilizarem o agressor pelo fato. Entretanto, os resultados significantes são compatíveis com Elssberg et al. ${ }^{1}$, que estudando violência doméstica contra mulheres em dez países da OMS constataram associações significativas entre experiências de violência e falta de saúde autorreportada.

Em relação às demais características das mulheres, note que a idade e o estado civil não influenciam a autopercepção de saúde das mulheres. No entanto, as mulheres (que se declaram) brancas e que residem na área urbana têm uma autopercepção positiva da saúde (boa e muito boa) em relação às mulheres não brancas; elas ainda possuem menor chance de perceberem a saúde como regular, ruim ou muito ruim.

As mulheres que possuem ao menos o ensino médio, apresentam melhor percepção de saúde, seja na área urbana ou rural do Brasil. No entanto, não se observa diferença entre as que residem em área rural e possuem ensino médio, ou supe- 
rior (completo ou incompleto) vis a vis as analfabetas em termos de percepção muito ruim da saúde.

Entre as que residem em área urbana, aquelas com maiores níveis de educação formal, apresentam um efeito positivo sobre a percepção de ter uma saúde muito boa. Entretanto, as que possuem ensino superior (incompleto ou completo) possuem menor chance de perceberem o estado de saúde como bom em relação as que são analfabetas; estas também percebem menos que seu estado de saúde é regular, ruim ou muito ruim em comparação com as menos escolarizadas.

Em relação às variáveis associadas às características econômicas (renda, chefe do domicílio e/ou ter plano de saúde) não se observa nenhuma diferença estatística entre as mulheres que residem em área rural. Por outro lado, o nível de renda domiciliar afeta positivamente a autopercepção de saúde das mulheres da área urbana. Todavia, em termos de magnitude o efeito é ínfimo.

Ao comparar as mulheres que possuem plano de saúde com as que não possuem, e que residem em área urbana, verifica-se que ter plano de saúde se relaciona positivamente com uma boa ou muito boa autopercepção de saúde. Ao mesmo tempo, em que ter plano também reduz a chance de ter uma percepção de saúde como regular, ruim ou muito ruim.

Os resultados para as mulheres chefe do domicílio são semelhantes aos observados para as que possuem plano de saúde (apenas para as residentes em áreas urbanas). Em termos de efeito, a chance de a mulher de referência do domicílio ter uma autopercepção regular, ruim ou muito ruim de saúde é menor do que as mulheres que não são. Por outro lado, estas possuem maior chance de autopercepção do estado de saúde como bom ou muito bom.

Quanto ao efeito regional, pode-se dizer que as mulheres que residem em áreas urbana ou rural nas regiões Centro-Oeste ou Sul possuem a mesma percepção de saúde que as mulheres que residem na região Sudeste. Ao passo que, as que residem no Norte e Nordeste do Brasil, possuem menor probabilidade de perceberem a saúde como boa ou muito boa, tanto em área rural quanto urbana. Além disso, pelas estimativas pode-se inferir que a mulher que reside em área urbana no Norte e Nordeste possui uma percepção pior do estado de saúde (regular, ruim ou muito ruim) em relação as mulheres do Sudeste.

Analisando as características dos domicílios (Abastecimento Água, Rede de esgoto, Destino lixo e Energia Elétrica), não se observa nenhum efeito sobre a autopercepção da saúde das mulheres, seja da área urbana ou rural. Ou seja, residir em domicílio, com ou sem, saneamento e energia elétrica, não afeta a percepção de saúde das mulheres.

De uma maneira geral, pode-se dizer que os resultados descritos acima corroboram com vários autores que concluíram em suas pesquisas que a autopercepção de saúde tende a ser mais elevada para as pessoas com melhores níveis socioeconômicos ${ }^{6,8,23-26}$.

Não se observa diferença significativa entre as mulheres que declaram ser fumantes e que fazem uso de bebida alcoólica. Por outro lado, verifica-se que ser mulher e fumante passiva (isto é, fuma quando alguém no domicílio fuma) afeta negativamente a boa percepção de saúde quando comparada às mulheres que não residem com fumantes, isso para as residentes em áreas urbanas (para as moradoras de áreas rurais, notou-se esse resultado apenas para as que apresentaram boa percepção).

A relação entre o estado de saúde e autoperceção de saúde é negativa, ou seja, as mulheres que informaram ter doença crônica possuem menor probabilidade de perceberem a saúde como boa ou muito boa.

Verifica-se que as mulheres que residem em área urbana e possuem baixo peso não diferem em autoavaliação do estado de saúde. No entanto, as que residem em área rural, possuem menor chance de perceber o estado de saúde como regular ou ruim. As mulheres da área urbana com peso normal (IMC entre 15,5 e 24,9) possuem maior chance de perceberem seu estado de saúde como muito bom ou bom; além de menor chance de ter uma autopercepção como regular, ruim ou muito ruim. Portanto, pode-se inferir que a correlação entre as medidas antropométricas e a autopercepção da saúde, apresenta resultados divergentes entre as mulheres residentes das áreas urbanas e rurais.

Pode-se dizer que, em relação à saúde e ao estilo de vida, não ter doença crônica, fumar, ser fumante passivo, praticar esporte e ter o peso corporal normal, favorece a melhor percepção da própria saúde da mulher que residem em áreas urbanas. Contudo, esse resultado diverge quando se avalia às moradoras de áreas rurais do Brasil.

De uma maneira geral, os resultados sugerem que residir nas regiões mais desenvolvidas do país, independente das demais características sociais, econômicas, de saúde e estilo de vida, melhora a autopercepção da saúde das mulheres, 
medida pela probabilidade de residir no Sudeste ou Sul. Alternativamente, as mulheres residentes no Nordeste do país, apresentaram piores percepções de sua saúde em comparação com as nortistas.

Por fim, um resultado que cabe destaque é que, a opção autopercepção de saúde reportada como regular apresenta os mesmos níveis de significância e efeito das opções ruim e muito ruim, apresentando apenas um efeito marginal numericamente maior. E, apesar dessa semelhança quanto aos resultados econométricos, para a amostra das urbanas quase $21,19 \%$ das entrevistadas declararam sua saúde como regular, enquanto $2,68 \%$ definiram como ruim e $0,63 \%$ como muito ruim. Já entre as entrevistadas residentes nos territórios rurais, 29,47\% julgam sua saúde como regular, $4,50 \%$ como ruim e $0,75 \%$ como muito ruim.

Por fim, cabe salientar que além dos resultados explorados nesta seção, foram estimados outros modelos, dentre os quais um apenas com mulheres com planos de saúde e outro sem as moradoras do Norte (foram realizados diversos exercícios, para subamostras).

\section{Considerações finais}

A investigação de como a violência afeta a saúde da mulher é ainda incipiente em virtude da insuficiência de estatísticas, em função da considerável subnotificação quanto aos relatos de violência contra a mulher. Diante disso, optouse por investigar o papel da violência na saúde da mulher a partir da autopercepção de saúde e da auto declaração das mulheres sobre violência, seja perpetrada por pessoa conhecida, desconhecida ou ambos.

Para realizar essa investigação, utilizam-se os microdados da PNS do ano de 2013, considerando as mulheres em idade reprodutiva (20 a 49 anos). Como fatores que podem afetar a autopercepção de saúde da mulher são considerados: as características da mulher (econômicas, demográficas e sociais), o local de residência (macrorregião brasileira) e se foi (ou não) vítima de violência.

A investigação empírica é realizada a partir da estimação de modelos logit ordenado, controlando pela área censitária em que reside. Isto é, são estimados modelos para as mulheres que residem em áreas urbana e rural do Brasil.

Em relação à violência, o foco é nas mulheres que foram vítimas de violência derivadas de agentes conhecidos da vítima. Ressaltando que, são utilizadas informações se a mulher sofreu violência e se a violência foi perpetrada por pessoa desconhecida.

A partir dos resultados, pode-se dizer que as mulheres que melhor avaliam sua saúde como boa são (autodeclaradas como) brancas, com maiores níveis de renda e de escolaridade, que não sofreram violência, não foram diagnosticadas com doença crônica, são pessoas de referência no domicílio, praticam esporte, fumam e tem peso normal. Portanto, merece destaque que as fumantes ativas percebem sua saúde como boa ou muito boa, enquanto as fumantes passivas apresentam piores percepções de sua própria saúde.

Os resultados são compatíveis com a hipótese de que existe correlação entre autopercepção de saúde e relato de vitimização. Contudo, as implicações são variantes com o tipo de relação que a mulher tem com o agressor. Para as residentes em áreas urbanas, a correlação é significativa para agressor conhecido, enquanto para as que residem em áreas rurais a sensibilidade volta-se para a agressão cometida por desconhecido.

Nesse lema, em se tratando de violência doméstica, a dependência financeira e a pobreza são alguns fatores desencadeantes (WHO, 1997, 2002). De acordo com WHO (2002), a mulher que sofre violência cometida por parceiro íntimo apresenta distorções em seu estado de saúde e, além disso, a violência contra as mulheres tem impactos de curto, médio e longo prazo, não só para as vítimas em si, mas também trazem efeitos traumáticos para as pessoas que testemunham a agressão, sobretudo quando se trata de crianças.

Por fim, pode-se concluir que a prevalência da violência esteja associada com a percepção que a mulher faz da própria saúde. Sendo assim, os esforços devem ser tanto na prevenção quanto no desenvolvimento e manutenção de respostas adequadas às vítimas de violência.

\section{Colaboradores}

MS Cruz e G Irffi participaram igualmente de todas as etapas de elaboração do artigo. 


\section{Referências}

1. Ellsberg M, Jansen HA, Heise L, Watts CH, Garcia-Moreno, C. Intimate partner violence and women's physical and mental health in the WHO multi-country study on women's health and domestic violence: an observational study. Lancet 2008; 371(9619):1165-1172.

2. Campbell JC. Health consequences of intimate partner violence. Lancet 2002; 359(9614):1331-1336.

3. Pinheiro RS, Viacava F, Travassos C, Brito AS. Gênero, morbidade, acesso e utilização de serviços de saúde no Brasil. Cien Saude Colet 2002; 7(4):687-707.

4. Abramsky T, Watts CH, Garcia-Moreno C, Devries K, Kiss L, Ellsberg M, Jansen HA, Heise L. What factors are associated with recent intimate partner violence? findings from the WHO multi-country study on women's health and domestic violence. BMC Public Health 2011; 11:109.

5. Pohlman A. Women, sexual violence and the Indonesian killings of 1965-66. London: Routledge; 2014.

6. Pinheiro RS, Viacava F, Travassos C, Brito AS. Gênero, morbidade, acesso e utilização de serviços de saúde no Brasil. Cien Saude Colet 2002; 7(4):687-707.

7. Prosenewicz I, Lippi UG. Access to health services, health conditions and exposure to risk factors: perception of riparian fishermen of the Machado River in Ji-Paraná, RO. Saúde Soc 2012; 21(1):219-231.

8. Santos, SR, Cunha AJLA, Gamba CM, Machado FG, Leal Filho JMM, Moreira NLM. Avaliação da assistência à saúde da mulher e da criança em localidade urbana da região Sudeste do Brasil. Rev Saude Publica 2000; 34(3):266-271.

9. Thum MA, Ceolin T, Borges AM, Heck RM. Saberes relacionados ao autocuidado entre mulheres da área rural do sul do Brasil. Revista Gaúcha de Enfermagem 2011;32(3):576-582.

10. Outlook. Violence Against Women. Effects on Reproductive Health. Outlook 2002; 20(1):1-8.

11. World Health Organization (WHO). Violence against women Health consequences, 1997. [acessado $2015 \mathrm{Fev}$ 25]. Disponível em: http://www.who.int/gender/violence/v8.pdf.

12. McCauley J, Yurk RA, Jenckes MW, Ford DE. Inside Pandora's box: abused women's experiences with clinicians and health services. J Gen Intern Med 1998; 13(8):549-555

13. Plichta SB, Falik M. Prevalence of violence and its implication for women's health. Women's Health Issues 2001; 11(3):244-258.

14. Whiffen VE, MacIntosh HB. Mediators of link between childhood sexual abuse and emotional distress: a clinical review. Trauma Violence Abuse 2005; 6(1):24-39.
15. World Health Organization (WHO). Multi-country study on women's health and domestic violence against women. Geneva: WHO; 2002.

16. Donnermeyer JF. Crime and violence in rural communities. In: Blaser SM, Blaser J, Pantoja K, organizadores. Perspectives on Violence and Substance Use in Rural America. Oakbrook: North Central Regional Educational Laboratory; 1995. p. 27-63.

17. Monsey B, Owen G, Zierman C, Lambert L, Hyman V. What Works in Preventing Rural Violence. St. Paul: Amherst H. Wilder Foundation; 1995.

18. Brant R. Assessing proportionality in the proportional odds model for ordinal logistic regression. Biometrics 1990; 46(4):1171-1178.

19. Greene W. Econometric Analysis. 5th ed. Upper Saddle River: Prentice Hall; 2003.

20. Long JS, Freese J. Regression Models for Categorical Dependent Variables Using Stata. 2nd ed. Boca Raton: Stata Press; 2006.

21. Williams R. Fitting heterogeneous choice models with oglm. Stata Journal 2010; 10:540-567.

22. Associação Brasileira de Empresas de Pesquisa (ABEP). Critério de classificação econômica Brasil. São Paulo: ABEP; 2015.

23. Santi LN, Nakano MAS, Lettiere A. Percepção de mulheres em situação de violência sobre o suporte e apoio recebido em seu contexto social. Texto \& Contexto-Enfermagem 2010; 19(3):417-424.

24. Kassouf AL. Acesso aos serviços de saúde nas áreas urbana e rural do Brasil. Revista de Economia e Sociologia Rural 2005; 43(1):29-44.

25. Thum MA, Ceolin T, Borges AM, Heck RM. Saberes relacionados ao autocuidado entre mulheres da área rural do sul do Brasil. Revista Gaúcha de Enfermagem 2011; 32(3):576-582.

26. Prosenewicz I, Lippi UG. Access to health services, health conditions and exposure to risk factors: perception of riparian fishermen of the Machado River in Ji-Paraná, RO. Saúde Soc 2012; 21(1):219-231.

Artigo apresentado em 11/09/2017

Aprovado em 10/10/2017

Versão final apresentada em 12/10/2017 